\title{
Cyst within the parenchyma of the optic chiasm
}

\author{
A. M. CHOWDHURY \\ From the Department of Ophthalmology, Maelor General Hospital, Wrexham
}

Various cysts associated with intraorbital and intracranial portions of the optic nerve have been described. Arachnoid cysts of the optic nerve in association with optic nerve glioma were described by Wolter and McKenney (1964); Holt (1966) described two cases of cysts of the intracranial portion of the optic nerve, and Smith, Hoyt, and Newton (1969) also described cysts of the anterior third of the left optic nerve. More recently Miller and Green (1975) described two cases of arachnoid cysts involving a portion of the intraorbital optic nerve, but until now a cyst within the parenchyma of the optic chiasm has not been seen.

\section{Materials and methods}

\section{CASE REPORT}

A 44-year-old White man attended the eye clinic because his vision had deteriorated during the previous

Address for reprints: A. M. Chowdhury, Department of Ophthalmology, Maelor General Hospital, Wrexham LLI 3 7TD three months, especially in the left eye, and he found progressive increased difficulty in near vision. $\mathrm{He}$ also had frontal headaches.

On examination his vision in the right eye was $6 / 18$ and in the left $6 / 24$ (Fig. I). With suitable correction the vision in the right eye could be improved to 6/12 but the vision in the left could not be changed. The intraocular pressure in both eyes was well within normal limits, his ocular movements were full, and he had a small exophoria with rapid recovery. His convergence and accommodation were within normal range and nothing abnormal could be detected externally or in the anterior chamber of either eye. His mediae were clear but in his fundi the optic discs were pale and atrophic. Plotting of his peripheral fields showed marked constriction of the visual fields, particularly temporally; the central fields also showed generalized constriction. The initial blood picture was within normal limits, Venereal Disease Reference Laboratory test, Reiter's protein complement-fixation test, and Treponema pallidum haemagglutin assays were all negative. Plain $x$-ray examination of the skull did not reveal any abnormality.

The patient was referred for neurosurgical opinion
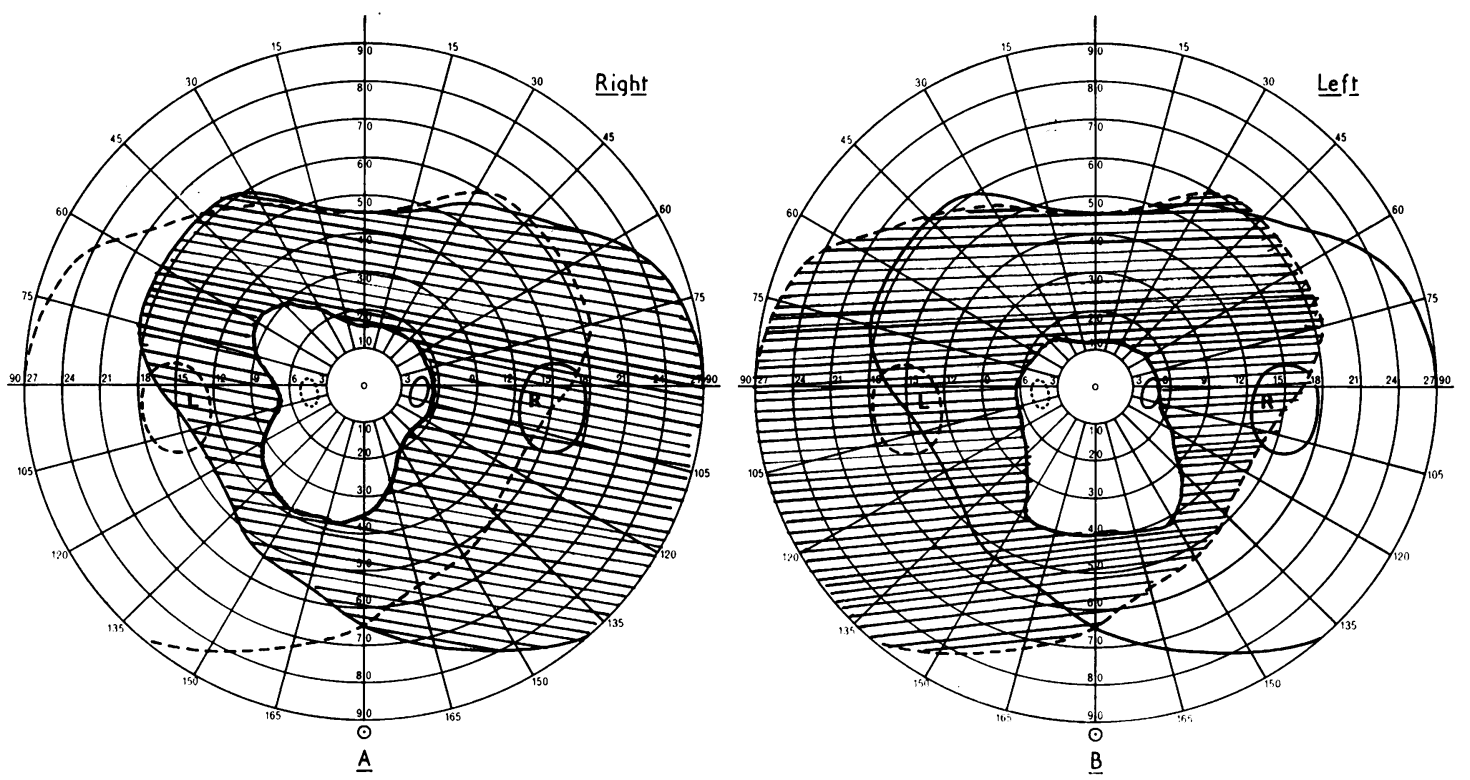

FIG. I Chart showing visual acuity on I I September 1975 


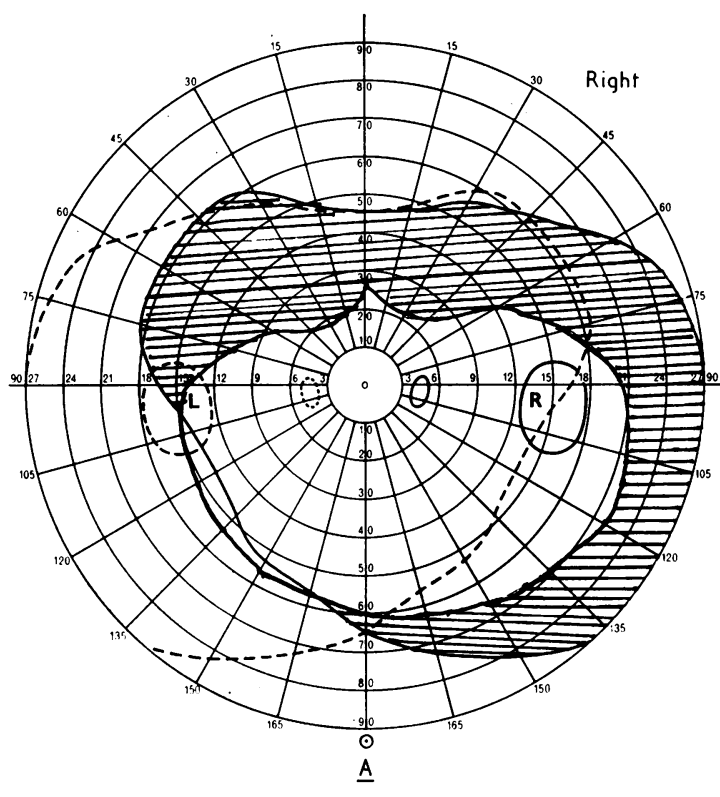

FIG. 2 Chart showing visual acuity on 29 December 1975

and was eventually admitted to the Regional Neurosurgical Centre where he was fully investigated.

Lumbar cerebrospinal fluid showed a clear, colourless fluid with $16 \mathrm{mg} / \mathrm{r} 00 \mathrm{ml}$ protein. Chest $x$-ray was normal. Plain $x$-ray of the abdomen showed no renal calculi. Skull $x$-ray was normal, although the dorsum sellae was a little porotic. Right carotid angiogram was normal. Lumbar air encephalogram showed some irregularity of the floor of the third ventricle in the region of the chiasm and suggested that there might be some thickening of the optic nerves, but this was not confirmed at operation.

It was felt that this man might have a lesion compressing the chiasm and so should have an exploratory craniotomy. On 4 November 1975 a right transfrontal craniotomy was performed and a cyst containing fluid was found lying within the parenchyma of the optic chiasm; it was not attached to any lesions either above or below the chiasm. The cyst was marsupialized and a section of the wall was taken for histological examination, but it showed only a few arachnoidal cells. There was no evidence of tumour in the specimen.

Postoperatively the patient recovered rapidly and his visual acuity steadily improved so that by the time he



was discharged from the Neurosurgical Unit he was able to read small print without much difficulty. On 29 December 1975 he was further checked in the eye unit and at that time his visual acuity was $6 / 5$ unaided in both eyes and, with a slight reading addition of + $0.75 \mathrm{D}$ sph., he could read $\mathrm{N}_{5}$ comfortably (Fig. 2). Further plotting of the visual fields showed considerable improvement.

\section{Summary}

Holt (I966) reporting on two cases mentioned the unusual finding of a cyst in the intracranial portion of the optic nerve. It produced ocular symptoms and signs of an intracranial lesion in one case and unilateral papilloedema in the other. The chiasmatic case which I have reported is exceptional and could be the first in the literature.

I am grateful for the report on operative findings by Mr R. V. Jeffreys, FRCS, at the Regional Neurosurgical Centre at Walton Hospital, Liverpool.

\section{References}

HOLt, н. (г966) Amer. F. Ophthal., 61, I 166

MILLER, N. R., and GREEN, w. R. (I975) Arch. Ophthal., 93, I I I 7

SMith, J. L., hOYT, W. F., and NEwTON, т. H. (1969) Amer. F. Ophthal., 68, 633

WOLTER, J. R., and MCKENNEY, M. J. (1964) Ibid., 57, I037 